\title{
CONCILIACIÓN \\ O CONTRADICCIÓN: CÓMO HACEN LAS MADRES TRABAJADORAS
}

\author{
Constanza Tobío Soler
}

Universidad Carlos III de Madrid

\begin{abstract}
RESUMEN
La rápida extensión de la actividad laboral femenina se acompaña en España de una escasa presencia del trabajo a tiempo parcial, de insuficientes servicios para el cuidado de niños y de una reducida participación de los hombres en el trabajo doméstico. En ese contexto, la pregunta que se plantea es cómo hacen las madres trabajadoras para compatibilizar en términos prácticos su doble responsabilidad laboral y familiar. A partir del concepto de estrategia se indaga en los recursos que en mayor medida facilitan la conciliación entre el mundo del trabajo y de la familia, señalándose asimismo sus limitaciones. Entre otros, se abordan la ayuda de la familia extensa, la ayuda remunerada, los centros escolares, las estrategias espaciales y las estrategias temporales. Se concluye que entre familia y empleo hay hoy una relación de contradicción que quienes la encarnan más directamente — las madres trabajadoras - resuelven de forma privada, informal y no siempre satisfactoria. La información utilizada se basa en la Encuesta sobre Compatibilización Familia-Empleo, realizada en 1998 a una muestra representativa de las madres trabajadoras españolas, complementada con datos de carácter cualitativo.
\end{abstract}

\section{INTRODUCCIÓN}

La generalización de la actividad laboral femenina constituye ya una nueva normalidad social en la mayor parte de los países europeos y occidentales (Rubery et al., 1998; Rubery et al., 1999). La participación de las mujeres españolas en el mercado de trabajo es menor que en el conjunto de los países de la Unión Euro- 
pea, pero las diferencias se van acortando rápidamente. En 1986 la tasa global de actividad femenina en Europa era del 39,9\% y la de España del 27,1\%; en 1997 los datos son, respectivamente, el 45,6 y 36,7\% (Fernández Cordón, 1999: 58). Es decir, la diferencia porcentual se ha reducido de 12,8 a 8,9 puntos. Pero más significativo que el aumento global de la actividad económica de las mujeres es el cambio de una pauta tradicional basada en el abandono del empleo en las edades en las que la mayoría de las mujeres tienen hijos pequeños a un nuevo modelo en el que, igual que los hombres, se mantienen en el mercado de trabajo a lo largo de toda la vida. Las edades centrales son especialmente significativas en este sentido: si en 1981 menos de un tercio de las mujeres de 35-39 años eran activas (28,2\%), en 1999 son más de dos tercios (64,0\%) (Fernández Cordón, 1999: 60). En veinte años, España ha pasado de un modelo familiar y laboral en que la división de roles de género era dominante a un nuevo modelo en que tanto mujeres como hombres participan directamente en el mundo del trabajo remunerado.

Se trata de un proceso de cambio tardío pero acelerado en el caso español, que plantea la necesidad de adaptar el conjunto de la organización social a la nueva situación. En otros países, los problemas que plantea la compatibilidad entre la vida familiar y laboral cuando hombres y mujeres trabajan se resuelven de diferentes maneras (Hantrais y Letablier, 1996: 124-135). En el norte de Europa predomina la yuxtaposición entre la vida laboral y las responsabilidades familiares en un marco general de políticas de igualdad entre mujeres y hombres. Los instrumentos principales para favorecer la compatibilidad familia-empleo son los centros para el cuidado colectivo de niños, los permisos parentales y la flexibilidad en el tiempo de trabajo, en especial a través de la extensión del tiempo parcial. Sin embargo, los efectos de estas medidas difieren en cuanto a los objetivos de igualdad de género ya que los permisos parentales y el trabajo a tiempo parcial son fundamentalmente femeninos. Francia representa un caso especial ya que a las tradicionales políticas de apoyo a la familia se superponen, a partir de los años setenta, otras que buscan facilitar a las madres trabajadoras el mantenimiento de su actividad económica. Hoy se reconoce el derecho de las mujeres a elegir entre quedarse en casa cuidando de los hijos o trabajar, siendo en ambos casos ayudadas por el Estado. La ayuda que reciben las madres que trabajan se concreta en redes de guarderías, escuelas maternales, asistentas maternales o ayuda doméstica remunerada; la ayuda que reciben las madres que deciden cuidar personalmente de sus hijos se concreta, a partir del segundo hijo, en un subsidio económico durante tres años (para cada hijo). El problema principal que plantea esta segunda opción es la reincorporación al mundo del trabajo una vez transcurrido ese período de apartamiento (Daune-Richard, 1993; Fagnani, 1998). En otros países como Alemania, la participación del Estado se limita a medidas de este último tipo que tienen como finalidad facilitar el abandono temporal de la actividad laboral de las madres mientras los hijos son pequeños, siendo prácticamente inexistentes los servicios de cuidado colectivo de niños. Aunque en gran parte de los países europeos la intervención estatal orientada a facilitar la conciliación entre la vida familiar y laboral es importante, en otros casos no es así. En Reino Unido e Irlanda, la inexistencia de políticas públicas orientadas a la familia se ha basado en 
un rechazo explícito a lo que se considera intromisión en la esfera de lo privado. A pesar de ello, la actividad laboral femenina es muy alta en el primer caso, pero tiene generalmente carácter secuencial, las madres abandonan el mundo del trabajo mientras los hijos son pequeños y es muy frecuente el trabajo a tiempo parcial.

En España, como en los restantes países del sur de Europa, la intervención estatal para favorecer la compatibilidad familia-empleo es también muy limitada, aunque recientemente ha habido algunos desarrollos legislativos destacables en aplicación de la Directiva europea 96/34AC/1996, sobre permisos parentales. La Ley 39/1999, de 5 de noviembre, para promover la conciliación de la vida familiar y laboral de las personas trabajadoras, incluye el derecho a un permiso laboral para cuidar a los hijos menores de ocho años durante un máximo de tres años, así como otro tipo de medidas que facilitan la compatibilidad entre las responsabilidades laborales y familiares. La nueva Ley representa el primer reconocimiento de los problemas que la creciente incorporación de las mujeres al mundo del trabajo plantea, pero probablemente sólo una minoría de padres y madres podrán acogerse a ella ya que los permisos que regula no están remunerados. A ello se añade una red de guarderías y servicios de cuidado de niños muy limitada (Valiente, 1997; Guillén, 1997), una escasa importancia del trabajo a tiempo parcial (Eurostat, 1995) y una escasa participación de los hombres españoles en el trabajo doméstico (Eurobarometre, 1991). La cuestión que se plantea es cómo hacen las mujeres españolas que trabajan y tienen hijos para hacer compatible su participación en ambos mundos. Ésta es la pregunta a la que se intenta responder en el presente artículo a partir de datos de la Encuesta de Compatibilización Familia-Empleo ${ }^{1}$ (ECFE), sobre las estrategias prácticas desarrolladas por las madres trabajadoras para compatibilizar ambos mundos, complementada con datos primarios cualitativos $^{2}$ basados en narraciones personales de mujeres en esa situación.

\section{TIPOS DE ESTRATEGIAS}

Como han puesto de relieve diversos estudios a lo largo de los últimos años (Durán, 1988; Ramos, 1990; Cruz Cantero, 1995), los hogares españoles

${ }^{1}$ La encuesta incluye 1.200 entrevistas representativas de las madres trabajadoras españolas. El error muestral es del 3\% para un nivel de confianza del 95\%. El trabajo de campo se hizo entre marzo y junio de 1998. Los resultados se tabularon y analizaron con el programa SPSS. La investigación se realizó en el marco del Programa Sectorial de Estudios del Género y de las Mujeres del III Plan Nacional de Investigación Científica y Desarrollo Tecnológico (Orden de 25 marzo 1996), ayuda sin la cual no hubiera sido posible.

${ }^{2}$ La investigación cualitativa se basa en seis grupos de discusión y veintiséis entrevistas en profundidad a madres trabajadoras que viven en pareja en Madrid, Barcelona, Valencia y Bilbao. El trabajo de campo se hizo entre los meses de septiembre y diciembre de 1995. Las variables principales para seleccionar a las entrevistadas fueron la edad y la condición socioeconómica, definida según la actividad laboral de la mujer. El análisis de contenido se realizó con el paquete informático QSR-Nudist. Esta investigación fue posible gracias a la subvención otorgada por el Instituto de la Mujer, del Ministerio de Asuntos Sociales, en el marco de la convocatoria para la realización de trabajos de investigación relacionados con la mujer (28 marzo 1994). 
siguen funcionando de manera marcadamente tradicional en lo que se refiere al reparto de las responsabilidades domésticas. Parece haber una superposición de roles viejos y nuevos que se manifiesta con especial intensidad en el caso de las madres trabajadoras. Los cambios en la posición económica y social de las mujeres escasamente se acompañan de cambios en la organización social y familiar. La sociedad y la familia siguen como siempre, como cuando el rol mayoritario de las mujeres era permanecer en el hogar a su cuidado. Se produce así una contradicción entre el nuevo rol laboral de las mujeres y la resistencia del contexto social a transformarse de acuerdo a la nueva situación, consecuencia de la mera superposición, en vez de integración, entre lo viejo y lo nuevo. Esa contradicción la están resolviendo hoy las propias mujeres que la encarnan más directamente, las trabajadoras que además son madres, a través de una variedad de estrategias, la mayor parte de las cuales son de carácter privado e informal.

El concepto de estrategia se utiliza aquí en el sentido que le da Commaille (1993) y en el contexto de las teorías que pretenden articular agencia y estructura (Bourdieu, 1980; Giddens, 1991). En períodos de cambio social la componente estratégica de la acción se acentúa. Los agentes no se limitan a reproducir de manera más o menos creativa situaciones estructurales, sino que se enfrentan a nuevos problemas que requieren nuevas soluciones. Es el caso de las madres de hoy que trabajan, quienes encarnan la contradicción entre los nuevos roles laborales de las mujeres y las formas tradicionales de organización doméstica. Utilizan distintas estrategias para superar la contradicción familiaempleo: estrategias principales, complementarias, extremas e indirectas.

Las estrategias principales son aquellas que por sí mismas son suficientes para responder a la totalidad de demandas que plantea la maquinaria doméstica. Frecuentemente, un miembro femenino de la red de parentesco, que suele ser la abuela materna, actúa como madre sustituta, asumiendo la mayor parte de las funciones que a la madre corresponden en el modelo de familia tradicional. En otras ocasiones es una persona ajena a la familia quien, a cambio de una remuneración económica, asume ese papel. La ayuda familiar o la ayuda doméstica remunerada pueden ser también piezas que complementan otras estrategias para hacer viable la actividad laboral de las madres. Los hombres parecen ser más y menos que una estrategia. Más porque, mirando hacia el futuro, la opinión mayoritaria de las madres trabajadoras entrevistadas es que los problemas que hoy se plantean se resolverán cuando los hombres participen activamente y en pie de igualdad en lo doméstico. En ese sentido, las entrevistadas relatan cómo están "educando» a sus maridos (y también a sus hijos) para que asuman, ideológicamente y prácticamente, las tareas que les corresponden de cuidado del hogar y de la familia, en reciprocidad con la nueva situación laboral de las mujeres. Sin embargo, los hombres, las parejas de las madres trabajadoras, parecen ser mucho menos que una estrategia, que un recurso con el que podar contar, ya que su ayuda en términos prácticos es todavía muy limitada.

Las estrategias complementarias son aquellas que por sí mismas no son generalmente suficientes para resolver todos los problemas que se plantean 
para hacer compatibles el empleo y la familia pero que, sin embargo, combinadas con otras, componen una estrategia general. A veces complementan una estrategia principal: por ejemplo, cuando la madre trabajadora con su familia se desplaza a vivir cerca, frecuentemente muy cerca, de su propia madre, para facilitar la ayuda cotidiana que ésta le presta. En otros casos, varias estrategias complementarias conforman una estrategia global. Estrategias complementarias son, por ejemplo, la utilización de centros escolares, la optimización del tiempo, la reducción de las distancias o la simplificación del trabajo doméstico.

No está claro si lo que se hace cuando no hay demasiada elección constituye una estrategia. Las estrategias extremas o indeseables son negativas, tanto para la madre como para los hijos, pero no por ello dejan de existir. Así, pueden considerarse prácticas como llevar a los hijos al trabajo cuando no hay otro sitio donde dejarlos, no ir al trabajo cuando los hijos están enfermos o dejarlos solos en casa cuando todavía son pequeños. Por último, las estrategias indirectas son aquellas prácticas en las que la compatibilidad se asegura eliminando o reduciendo una parte del problema: los hijos o el empleo.

Este artículo se centra en las estrategias que las propias madres trabajadoras señalan como las que más las ayudan a hacer compatible el trabajo y la familia. Ello incluye la ayuda de la red familiar, la ayuda doméstica remunerada, la ayuda de la pareja masculina, vivir cerca del trabajo o del colegio de los hijos, el horario de trabajo y los servicios que ofrecen los centros escolares ${ }^{3}$.

\section{TABLA 1}

Qué ayuda más a las madres trabajadoras a hacer familia y empleo compatible (Los datos se refieren a todas las madres trabajadoras que viven con al menos un hijo de menos de 18 años)

La ayuda de su madre 26,7

La ayuda de su marido/pareja

24,7

Vivir cerca del trabajo

13,9

La ayuda de otros miembros de la familia

10,2

La ayuda doméstica remunerada

9,2

El horario de trabajo

7,8

Vivir cerca del colegio de los niños

4,4

Los servicios que ofrece el centro escolar

1,5

Otros recursos

0,7

Nada

0,8

TOTAL

Fuente: Encuesta de Compatibilización Familia-Empleo.

${ }^{3}$ Sobre las restantes estrategias, ver Tobío (1998) y Tobío et al. (1996 y 1998). Sobre las estrategias de las madres trabajadoras en situación de monoparentalidad, Tobío y Fernández Cordón (1999). 


\section{LA AYUDA DE LA FAMILIA EXTENSA}

Según datos de la ECFE, más de tres de cada cuatro madres que trabajan $(77 \%)$ tienen un familiar próximo viviendo en la misma localidad. En el 56\% de los casos es su propia madre, en el 44\% el padre, 43\% la suegra y $37 \%$ el suegro. La mitad de las madres trabajadoras cuya madre vive en la misma localidad vive en el mismo barrio que ella, pero raramente en la misma casa (11\%). La excepción, según datos censales, son las madres solas — que no viven con una pareja masculina-, quienes frecuentemente (29\% de los casos) viven con su madre. Las diferencias según el estado civil (que en buena parte reflejan la edad) son muy acusadas: más de la mitad de las madres solteras $(60 \%)$ viven con su madre, porcentaje que se reduce a un $10 \%$ en el caso de las viudas.

\section{TABLA 2}

Núcleos familiares según tipo. España, 1991

(Los datos se refieren a madres con al menos un hijo de menos de 18 años y proceden del Censo de Población de 1991)

\begin{tabular}{|c|c|c|c|c|c|c|}
\hline & $\begin{array}{l}\text { Casadasl } \\
\text { En pareja }\end{array}$ & $\begin{array}{l}\text { Madres } \\
\text { solas } \\
\text { Solteras }\end{array}$ & $\begin{array}{c}\text { Madres } \\
\text { solas } \\
\text { Divorciadas }\end{array}$ & $\begin{array}{l}\text { Madres } \\
\text { solas } \\
\text { Viudas }\end{array}$ & $\begin{array}{c}\text { Madres } \\
\text { solas } \\
\text { Todas }\end{array}$ & TOTAL \\
\hline Hogares con un núcleo ........ & 85,9 & 27,9 & 63,8 & 75,7 & 59,3 & 83,9 \\
\hline Núcleo con otros .................. & 14,1 & 72,1 & 36,2 & 24,3 & 40,7 & 16,1 \\
\hline - Sin abuela ..................... & 11,0 & 12,4 & 9,9 & 14,3 & 11,6 & 11,0 \\
\hline — Con abuela .................... & 3,2 & 59,7 & 26,3 & 10,1 & 29,1 & 5,1 \\
\hline TODOS & 100 & 100 & 100 & 100 & 100 & 100 \\
\hline
\end{tabular}

Fuente: Fernández Cordón y Tobío (1998: 67).

Las estrategias espaciales complementarias para vivir cerca de la abuela son algo más importantes entre madres trabajadoras de nivel socioeconómico bajo. Las que residen en la misma casa se elevan a un 13\% (frente a un 5\% entre las de nivel alto). Las que viven en otro barrio son menos de la mitad (47\%), que aumenta a casi dos tercios (59\%) entre las de nivel alto.

La ayuda de las abuelas está claramente asociada a la proximidad espacial de sus hijas y nietos. Tres de cada cuatro madres trabajadoras cuya madre vive en la misma casa, edificio o calle son ayudadas por ella en el cuidado de los hijos. La cifra baja a un $51 \%$ para aquellas que viven en el mismo barrio y a un $38 \%$ para las que lo hacen en la misma localidad pero en otro barrio. 


\section{TABLA 3}

\section{Lugar de residencia de la madre de la entrevistada por nivel socioeconómico de la entrevistada}

(Base=entrevistadas con madres residentes en la misma localidad)

(Porcentajes verticales)

\begin{tabular}{|c|c|c|c|c|}
\hline & $\begin{array}{c}\text { Nivel socio- } \\
\text { económico } \\
\text { alto }\end{array}$ & $\begin{array}{l}\text { Nivel socio- } \\
\text { económico } \\
\text { medio }\end{array}$ & $\begin{array}{l}\text { Nivel socio- } \\
\text { económico } \\
\text { bajo }\end{array}$ & TOTAL \\
\hline 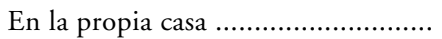 & 4,8 & 11,7 & 13,2 & 10,9 \\
\hline En el mismo edificio ......................... & 4,0 & 3,4 & 6,4 & 4,5 \\
\hline En la misma calle ............................. & 5,6 & 2,2 & 3,6 & 3,3 \\
\hline En el mismo barrio .......................... & 26,4 & 28,7 & 30,0 & 28,7 \\
\hline 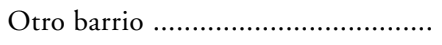 & 59,2 & 54,0 & 46,8 & 52,6 \\
\hline 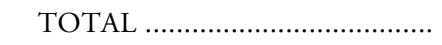 & 100 & 100 & 100 & 100 \\
\hline
\end{tabular}

Fuente: Encuesta de Compatibilización Familia-Empleo (chi cuadrado significativo al 0,071; 1 casilla $[6,7 \%]$ tiene una frecuencia esperada $<5)$.

\section{TABLA 4}

Abuelas maternas que cuidan a los nietos según lugar de residencia (Los datos se refieren a entrevistadas cuya madre vive en la misma localidad, $\mathrm{N}=673$ ) (Porcentajes verticales)

\begin{tabular}{|c|c|c|c|c|c|}
\hline & $\begin{array}{c}\text { La misma } \\
\text { casa }\end{array}$ & $\begin{array}{c}\text { El mismo } \\
\text { edificio }\end{array}$ & $\begin{array}{c}\text { La misma } \\
\text { calle }\end{array}$ & $\begin{array}{c}\text { El mismo } \\
\text { barrio }\end{array}$ & $\begin{array}{l}\text { La misma } \\
\text { localidad }\end{array}$ \\
\hline Abuelas que cuidan a los nietos ............. & 79,2 & 56,7 & 72,7 & 51,3 & 37,6 \\
\hline Abuelas que no cuidan a los nietos ........ & 20,8 & 43,3 & 27,3 & $48 ., 7$ & 62,4 \\
\hline TOTAL & 100 & 100 & 100 & 100 & 100 \\
\hline
\end{tabular}

FUENTE: Encuesta de Compatibilización Familia-Empleo (chi cuadrado significativo al 0,000; 0 casilla frecuencia esperada $<5$ ).

La mayor parte de la ayuda que proporcionan los abuelos tiene que ver con el cuidado de sus nietos. En casi la mitad de los casos (46\%) la abuela materna cuida cotidianamente a los hijos en edad preescolar (cuando viven en la misma localidad y la madre trabajadora tiene al menos un hijo de menos de 6 años). En otro 38\% de los casos la abuela materna se encarga del cuidado de los nietos cuando vuelven a casa después del colegio, bien en su propia casa o en la de su hija. A menudo (25\%) preparan comida para toda la familia de sus hijas o llevan a los nietos a su centro escolar y los recogen a la salida (19\%). 
Diferentes autores han señalado el hecho de que la ayuda de la generación precedente se recibe generalmente a través de la línea femenina, aunque la ayuda a través de la línea masculina puede ser importante en ocasiones (Bloch y Buisson, 1996). La gran encuesta sobre los abuelos en Francia realizada por Attias-Donfut y Segalen (1998) muestra que la relación entre las abuelas y sus hijas que también son madres es mucho más intensa y frecuente que la que se da entre abuelas-hijos, abuelos-hijas o abuelos-hijos.

En el caso español, la ayuda de la generación anterior parece seguir una doble lógica de consanguinidad y de género. Por una parte, los parientes consanguíneos ayudan siempre más que los políticos (desde la perspectiva de la madre trabajadora). Las madres ayudan más que las suegras y los padres más que los suegros. Por otra parte, las mujeres ayudan más que los hombres, lo cual explica por qué las madres ayudan más que los padres y las suegras más que los suegros. Por ejemplo, como ya se ha mencionado, el 19\% de las abuelas maternas llevan y traen a sus nietos del centro escolar, porcentaje que se reduce a un $11 \%$ en el caso de los abuelos maternos, a un $9 \%$ en el de las abuelas paternas y a un $5 \%$ en el de los abuelos paternos. Esta misma jerarquía se reproduce en la mayor parte de las tareas.

La ayuda de los abuelos parece ser menos autónoma que la de las abuelas. Es más importante cuando viven con su mujer, probablemente porque ésta es quien organiza el cuidado de los nietos y les anima a participar. Los abuelos se especializan en diferentes tipos de tareas, como llevar o traer a los niños al colegio y cuidarlos cuando vuelven; raramente se encargan de la preparación de comida, realizan tareas de limpieza o llevan a los nietos al médico. Por el contrario, las abuelas maternas son los únicos parientes que ayudan de forma significativa en tareas domésticas no directamente relacionadas con el cuidado de los nietos, como limpiar, planchar o coser.

La ayuda de otros parientes diferentes de los abuelos es mucho más escasa, casi inexistente en el caso de otros parientes masculinos. Los mayores porcentajes corresponden al cuidado de niños después del colegio o de niños en edad preescolar por parte de parientes femeninos diferentes de las abuelas, sin sobrepasar en ninguno de los dos casos el $10 \%$.

La ayuda de la red familiar se hace todavía más importante en ocasiones extraordinarias, que de hecho no lo son tanto. Dos tercios de las madres trabajadoras cuentan con la ayuda de sus propias madres, cuando viven en la misma localidad, en situaciones como enfermedades de los hijos, vacaciones escolares, quedarse con los hijos por las noches cuando los padres salen o algún fin de semana. Los porcentajes para los restantes miembros de la generación anterior son: $40 \%$ abuelos maternos, $36 \%$ abuelas paternas, $22 \%$ abuelos paternos. La ayuda de otro tipo de parientes femeninos es más importante en ocasiones extraordinarias que en ordinarias: hermanas, tías o cuñadas ayudan frecuentemente cuando se plantea una situación de este tipo. La ayuda de parientes masculinos es, por el contrario, mucho menos frecuente. 


\section{TABLA 5}

Ayuda que aporta la red familiar de las madres trabajadoras en tareas domésticas ordinarias

(Porcentaje de madres trabajadoras con parientes que residen en su misma localidad que son ayudadas por ellos)

\begin{tabular}{|c|c|c|c|c|c|c|}
\hline Tipo de tarea & $\begin{array}{l}\text { Abuela } \\
\text { materna }\end{array}$ & $\begin{array}{l}\text { Abuelo } \\
\text { materno }\end{array}$ & $\begin{array}{l}\text { Abuela } \\
\text { paterna }\end{array}$ & $\begin{array}{l}\text { Abuelo } \\
\text { paterno }\end{array}$ & $\begin{array}{c}\text { Otros } \\
\text { parientes } \\
\text { femeninos }\end{array}$ & $\begin{array}{c}\text { Otros } \\
\text { parientes } \\
\text { masculinos }\end{array}$ \\
\hline $\begin{array}{l}\text { Cuidar niños en edad pre- } \\
\text { escolar }\end{array}$ & 31,3 & 18,8 & 15,0 & 7,4 & 6,6 & 2,2 \\
\hline $\begin{array}{l}\text { Cuidar niños después del co- } \\
\text { legio }\end{array}$ & 38,2 & 15,7 & 17,5 & 8,5 & 8,1 & 2,8 \\
\hline Llevar/traer niños al colegio & 18,6 & 10,6 & 8,9 & 4,7 & 5,6 & 0,6 \\
\hline $\begin{array}{l}\text { Preparar comida para los } \\
\quad \text { niños }\end{array}$ & 23,0 & 4,5 & 6,0 & 1,1 & 3,2 & 0,1 \\
\hline $\begin{array}{l}\text { Preparar comida para entre- } \\
\quad \text { vistada }\end{array}$ & 18,3 & 2,2 & 3,1 & 0 & 1,9 & 0 \\
\hline $\begin{array}{l}\text { Preparar comida marido en- } \\
\text { trevistada }\end{array}$ & 11,9 & 1,5 & 3,1 & 0,2 & 1,3 & 0 \\
\hline Limpiar la casa ..................... & 9,4 & 0,7 & 1,7 & 0 & 3,2 & 0,4 \\
\hline 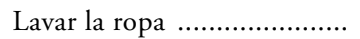 & 8,6 & 0,4 & 1,7 & 0 & 2,7 & 0,3 \\
\hline 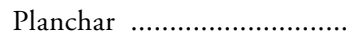 & 8,8 & 0,2 & 2,3 & 0 & 1,6 & 0,1 \\
\hline 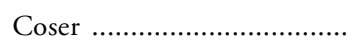 & 8,2 & 0,2 & 1,4 & 0 & 2,1 & 0,1 \\
\hline Hacer la compra ................... & 8,6 & 0,7 & 2,5 & 0 & 1,8 & 0,1 \\
\hline Llevar a los niños al médico .. & 8,6 & 1,9 & 3,9 & 0,1 & 1,8 & 0,1 \\
\hline Ninguna tarea ........................ & 46,2 & 73,8 & 75,9 & 87,4 & 87,4 & 95,3 \\
\hline
\end{tabular}

FUENTE: Encuesta de Compatibilización Familia-Empleo.

En cuanto a las situaciones extraordinarias relacionadas con los hijos, la proximidad espacial no es una condición necesaria respecto de la ayuda que proporcionan los abuelos. Aunque los que viven más cerca ayudan más, también los que viven lejos -incluso a veces en otra localidad- lo hacen. Por ejemplo, el $57 \%$ de las madres trabajadoras son ayudadas por sus madres residentes en la misma localidad pero en otro barrio.

La percepción de las madres trabajadoras acerca de la ayuda que reciben de la red familiar es coherente con las prácticas observadas. Para dos tercios de las entrevistadas, es al menos bastante importante. Es especialmente importante para las más jóvenes (de menos de 30 años), para las de menor nivel socioeconómico y para las madres solas. 


\section{TABLA 6}

Ayuda que aporta la red familiar de las madres trabajadoras en tareas domésticas extraordinarias de cuidado de niños

(Porcentaje de madres trabajadoras con parientes que residen en su misma localidad que son ayudadas por ellos)

\begin{tabular}{|c|c|c|c|c|c|c|}
\hline Tipo de tarea & $\begin{array}{l}\text { Abuela } \\
\text { materna }\end{array}$ & $\begin{array}{l}\text { Abuelo } \\
\text { materno }\end{array}$ & $\begin{array}{l}\text { Abuela } \\
\text { paterna }\end{array}$ & $\begin{array}{l}\text { Abuelo } \\
\text { paterno }\end{array}$ & $\begin{array}{c}\text { Otros } \\
\text { parientes } \\
\text { femeninos }\end{array}$ & $\begin{array}{c}\text { Otros } \\
\text { parientes } \\
\text { masculinos }\end{array}$ \\
\hline En fines de semana .............. & 29,9 & 20,4 & 13,8 & 9,6 & 6,8 & 2,3 \\
\hline $\begin{array}{l}\text { Por la noche cuando salen los } \\
\text { padres }\end{array}$ & 33,7 & 18,9 & 16,7 & 11,2 & 8,9 & 2,5 \\
\hline 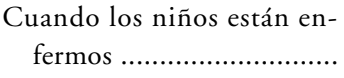 & 41,6 & 21,9 & 16,7 & 9,9 & 8,4 & 2,2 \\
\hline $\begin{array}{l}\text { Durante las vacaciones esco- } \\
\text { lares }\end{array}$ & 33,0 & 19,8 & 13,8 & 8,5 & 6,6 & 1,2 \\
\hline $\begin{array}{l}\text { Si la persona que los cuida no } \\
\text { está disponible }\end{array}$ & 11,7 & 6,5 & 5,3 & 3,4 & 5,6 & 0,9 \\
\hline 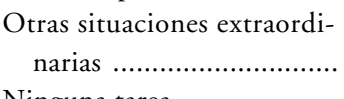 & 38,9 & 22,8 & 18,3 & 12,6 & 11,5 & 5,2 \\
\hline
\end{tabular}

Fuente: Encuesta de Compatibilización Familia-Empleo.

\section{TABLA 7}

Opinión acerca de la importancia de la ayuda familiar por edad de la entrevistada (Base $=$ entrevistadas con red familiar en su localidad) (Porcentajes verticales)

\begin{tabular}{|c|c|c|c|c|}
\hline Tipo de tarea & $<30$ & $30-39$ & $>39$ & TOTAL \\
\hline Sin su ayuda no podría trabajar ....... & 37,3 & 18,5 & 4,9 & 16,8 \\
\hline 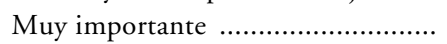 & 31,7 & 30,8 & 17,5 & 26,5 \\
\hline Importante o bastante importante .. & 17,5 & 24,8 & 13,6 & 20,4 \\
\hline Poco o nada importante ..................... & 13,5 & 26,0 & 64,0 & 36,2 \\
\hline TOTAL …….......................... & 100 & 100 & 100 & 100 \\
\hline
\end{tabular}

Fuente: Encuesta de Compatibilización Familia-Empleo (chi cuadrado significativo al 0,000; 0 casilla frecuencia esperada $<5$ ). 


\section{TABLA 8}

Opinión acerca de la importancia de la ayuda familiar por nivel socioeconómico de la entrevistada

(Base=entrevistadas con red familiar en su localidad) (Porcentajes verticales)

\begin{tabular}{ccccc}
\hline Tipo de tarea & Alto & Medio & Bajo & TOTAL \\
\hline Sin su ayuda no podría trabajar ....... & 10,8 & 13,4 & 24,2 & 16,8 \\
Muy importante .......................... & 32,5 & 29,7 & 19,7 & 26,5 \\
Importante o bastante importante ... & 18,1 & 20,5 & 21,7 & 20,4 \\
Poco o nada importante ................... & 38,6 & 36,4 & 34,4 & 36,2 \\
\cline { 2 - 5 } TOTAL ...................................... & 100 & 100 & 100 & 100 \\
\hline
\end{tabular}

Fuente: Encuesta de Compatibilización Familia-Empleo (chi cuadrado significativo al 0,000; 0 casilla frecuencia esperada $<5$ ).

\section{TABLA 9}

Opinión acerca de la importancia de la ayuda familiar por situación familiar de la entrevistada

(Base $=$ entrevistadas con red familiar en su localidad) (Porcentajes verticales)

\begin{tabular}{|c|c|c|c|c|c|}
\hline Tipo de tarea & $\begin{array}{c}\text { Con pareja } \\
\text { e hijos }\end{array}$ & $\begin{array}{c}\text { Con pareja } \\
\text { hijos y } \\
\text { pariente }\end{array}$ & $\begin{array}{c}\text { Sin pareja } \\
\text { con hijos }\end{array}$ & $\begin{array}{c}\text { Sin pareja, } \\
\text { con hijos y } \\
\text { pariente }\end{array}$ & TOTAL \\
\hline Sin su ayuda no podría trabajar .............. & 14,9 & 20,7 & 17,4 & 60,0 & 16,8 \\
\hline Muy importante ......................... & 25,4 & 36,6 & 27,5 & 24,0 & 26,5 \\
\hline Importante o bastante importante ......... & 21,6 & 20,7 & 11,6 & 8,0 & 20,4 \\
\hline 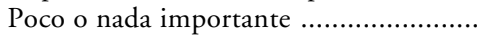 & 38,0 & 22,0 & 43,5 & 8,0 & 36,2 \\
\hline TOTAL & 100 & 100 & 100 & 100 & 100 \\
\hline
\end{tabular}

FUENTE: Encuesta de Compatibilización Familia-Empleo (chi cuadrado significativo al 0,000; 1 casilla $[6,3 \%]$ frecuencia esperada $<5)$.

La abuela materna se señala como la persona principal que aporta ayuda para dos tercios de las entrevistadas para las que la ayuda de la familia extensa es importante. En segundo lugar se señala la suegra; en tercer lugar, otros parientes femeninos, y en cuarto lugar, los parientes masculinos. Ello permite matizar lo visto anteriormente en cuanto a la ayuda que prestan unos y otros. La ayuda de los abuelos, probablemente, no es comparable en términos de importancia relativa a la que prestan las abuelas, cuya disponibilidad parece ser 
mucho más amplia y tener un carácter más polivalente. La percepción diferencial de la ayuda que prestan unos y otros, que parece oponerse al ranking de tareas que realizan, es coherente con las menciones en los discursos de las madres trabajadoras en la investigación cualitativa, en la que la presencia de los abuelos es muy reducida y, cuando aparece, suele limitarse a tareas auxiliares encomendadas por sus cónyuges.

—ENTREVISTADORA: ¿Quién cuida a vuestros hijos cuando estáis trabajando?

- Mi madre.

- A mi, mi madre.

- A mi, mi madre

—Las abuelas, ¿no?

- Mi hermana.

(Grupo de discusión, madres trabajadoras, Madrid, nivel socioeconómico bajo, 20-29 años.)

\section{LA AYUDA DOMÉSTICA REMUNERADA}

Los hogares de clase alta tradicionalmente han tenido trabajadores de diferente tipo como forma normal de organizar la vida doméstica, con independencia de las actividades de la esposa. De hecho, las mujeres de clase alta generalmente han tenido una intensa actividad social fuera del hogar o desde éste como espacio público, de mantenimiento del estatus o de promoción de la actividad profesional del hombre. Esto continúa siendo así en gran medida y significa, desde el punto de vista de las mujeres de este origen social que se incorporan hoy al mundo del trabajo, que los problemas de compatibilización entre ambos mundos son escasos, casi inexistentes. La infraestructura doméstica que siempre ha existido permite la ausencia de la mujer del hogar, ahora más frecuentemente por motivos laborales. E incluso cuentan a menudo con sus propias madres, generalmente disponibles para tareas de supervisión o, como se vio anteriormente, en situaciones extraordinarias.

Cuando eran más pequeños, pues aparte de que he tenido en todo momento [...] una chica que los cuidaba, digamos fija, y aparte una interna... Y encima mi madre vivía en el piso de al lado, no tenía ningún problema.

(Entrevista en profundidad, madre trabajadora, Bilbao, nivel socioeconómico alto, 40-49 años.)

Lo hace todo ella [la chica]. Viene a las nueve de la mañana y se va a las nueve de la noche.

(Entrevista en profundidad, Bilbao, nivel socioeconómico alto, 30-39 años.) 
Bueno, yo tengo una señora. Y luego tengo una chica para el niño.

(Entrevista en profundidad, madre trabajadora, Madrid, nivel socioeconómico alto, 40-49 años.)

En otros casos, la ayuda doméstica a tiempo completo constituye una estrategia mucho más consciente e incluso arriesgada. Se trata de las mujeres que perciben que traspasar el trabajo doméstico a otra persona a cambio de una remuneración es liberar tiempo para sí mismas, así como una condición para el desarrollo de la propia carrera profesional. Se trata de una apuesta difícil, ya que se produce un conflicto de presente entre la lógica familiar, ahorrar en ese capítulo para poder gastar en otros consumos familiares, y la lógica individual de la mujer, según la cual hay que invertir en el presente para lograr un beneficio probable - pero no asegurado - en el futuro, lo cual exige una elevada disponibilidad laboral. Esa decisión exige una notable seguridad por parte de la mujer en su carrera profesional, ya que pesa la idea de que la ayuda doméstica es un gasto del que se puede prescindir. Es, por ejemplo, el caso de una entrevistada de origen modesto y brillante carrera profesional que ha alcanzado un alto cargo en una gran empresa, de mayor estatus y remuneración que el trabajo de su marido.

- Me quedaba yo con los niños y decidi que no, que prefería quitármelo de otra parte... Nunca he aceptado quitar la ayuda [remunerada] trabajando yo... [...] ... siempre parece que es el parámetro más importante, bueno más caro, la persona que puedas tener de ayuda. Siempre tiendes a: "esto lo reduzco, esto lo quito". Por eso he mantenido la cabeza fría ahi, y he dicho que ni hablar. Que ni hablar, que antes preferia... comer patatas que quitarme eso.

-ENTREVISTADORA: ¿Porque eso hubiera repercutido negativamente en tu trabajo?

- Por supuesto, por supuesto. [...] Siempre he tenido un trabajo bastante atipico, he tenido un trabajo con muchisima presión, con muchismo estrés. Un trabajo atipico para la mujer. Las circunstancias se me han presentado asi, nunca he aspirado a ocupar un puesto equis... Y nunca he dicho que no; $o$ sea, he aceptado todos los retos que se me han presentado.

(Entrevista en profundidad, madre que trabaja, nivel socioeconómico alto, Madrid, 40-49 años.)

Algo más de la cuarta parte de las madres que trabajan y tienen hijos de menos de 18 años (28\%) cuentan con algún tipo de ayuda doméstica remunerada. En la mayor parte de los casos (73\%) se trata de una ayuda puntual, limitada a unas horas a la semana. Las entrevistadas que cuentan con una ayuda diaria representan solamente el 6\% de las mismas. La existencia de ayuda remunerada está fundamentalmente asociada al nivel socioeconómico: más de la mitad de las de nivel alto (54,5\%) cuentan con ella, así como el $29,5 \%$ de las de nivel medio y sólo el $11,5 \%$ de las de nivel bajo. 


\section{TABLA 10}

Existencia de ayuda doméstica remunerada por nivel socioeconómico de las entrevistadas

(Porcentajes verticales)

\begin{tabular}{|c|c|c|c|c|}
\hline Ayuda doméstica remunerada & Nivel alto & Nivel medio & Nivel bajo & TOTAL \\
\hline Tienen .............. & 54,5 & 29,5 & 11,5 & 27,6 \\
\hline No tienen & 45,5 & 70,5 & 88,5 & 72,4 \\
\hline TOTAL & 100 & 100 & 100 & 100 \\
\hline
\end{tabular}

FUENTE: Encuesta de Compatibilización Familia-Empleo (chi cuadrado significativo al 0,000; 0 casilla frecuencia esperada $<5)$.

La segunda variable que determina de forma importante la existencia de ayuda doméstica remunerada es el número de horas de trabajo de la entrevistada. Por debajo de treinta horas a la semana, sólo el $12 \%$ de las madres trabajadoras cuenta con ayuda de este tipo. Hay que tener en cuenta, sin embargo, que la mayoría $(81 \%)$ de las entrevistadas trabaja más de treinta horas semanales y que el número de horas de trabajo está estadísticamente asociado al nivel socioeconómico, ya que sólo el $9 \%$ de las madres trabajadoras de nivel alto tiene una jornada inferior a treinta horas por semana.

\section{TABLA 11}

Existencia de ayuda doméstica remunerada por número de horas de trabajo de las entrevistadas

(Porcentajes verticales)

\begin{tabular}{|c|c|c|c|c|}
\hline Ayuda doméstica remunerada & $<30$ & $30-39$ & $>39$ & TOTAL \\
\hline Tienen & 12,3 & 32,6 & 19,7 & 27,6 \\
\hline 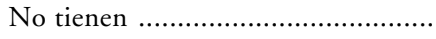 & 87,7 & 67,4 & 80,3 & 72,4 \\
\hline (n) & 100 & 100 & 100 & 100 \\
\hline
\end{tabular}

FUENTE: Encuesta de Compatibilización Familia-Empleo (chi cuadrado significativo al 0,000; 0 casilla frecuencia esperada $<5)$.

Aunque las variables que más claramente determinan la decisión de pagar a alguien para que asuma parte de las tareas domésticas son el nivel socioeconómico y la jornada laboral, hay otras tres variables que también ejercen una influencia destacable. En primer lugar, la situación familiar, siendo los hogares forma- 
dos por una pareja con hijos los que más frecuentemente cuentan con ayuda remunerada, excepto cuando a ese núcleo básico se añade otra persona, que muy frecuentemente es la abuela. Los hogares formados por madres solas con hijos raramente tienen ayuda doméstica remunerada. En segundo lugar, ejerce también una influencia el número de hijos menores de dieciocho años que conviven con las entrevistadas. El $24 \%$ de las que tienen un hijo cuenta con ayuda remunerada, proporción que aumenta a un 33\% entre las que tienen dos hijos. En tercer lugar, hay que mencionar la ayuda de la red familiar, concretada en la ayuda de la abuela materna. No se ha observado relación entre la ayuda que ésta proporciona en tareas de cuidado de los hijos o de elaboración de comida y la existencia de ayuda remunerada, pero sí, en cambio, en lo que se refiere a tareas de limpieza y cuidado de la ropa. Es decir, la ayuda remunerada parece centrarse fundamentalmente en este tipo de tareas duras, más que en el cuidado de niños, que básicamente asume la familia, nuclear o extensa. La excepción es esa minoría que cuenta con servicio doméstico a tiempo completo.

\section{TABLA 12}

Existencia de ayuda doméstica remunerada según ayuda de las abuelas en limpiar la casalcuidar la ropa

(Porcentajes verticales)

\begin{tabular}{|c|c|c|c|}
\hline Ayuda doméstica remunerada & Abuela ayuda & Abuela no ayuda & TOTAL \\
\hline 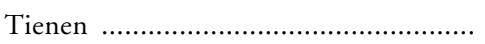 & 15,8 & 28,4 & 27,6 \\
\hline 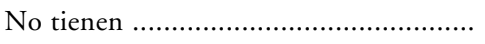 & 84,2 & 71,6 & 72,4 \\
\hline 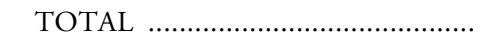 & 100 & 100 & 100 \\
\hline
\end{tabular}

FUENTE: Encuesta de Compatibilización Familia-Empleo (chi cuadrado significativo al 0,008; 0 casilla frecuencia esperada $<5$ ).

Las tres funciones ordinarias que con más frecuencia realiza la ayuda doméstica remunerada son limpiar la casa $(85,5 \%)$, planchar $(58 \%)$ y lavar y tender la ropa $(51 \%)$. Las dos funciones que realiza con menos frecuencia la persona que a cambio de un salario ayuda en las tareas domésticas son llevar a los niños al médico $(7 \%)$ y hacer la compra (11\%).

Los diferentes tipos de ayuda doméstica remunerada asumen diferentes tipos de funciones domésticas. Las internas y las externas a tiempo completo mayoritariamente se encargan de la limpieza de la casa, del cuidado de los hijos y de la preparación de comida para todos los miembros de la familia. Menos frecuente es su dedicación a la costura y al arreglo de la ropa, la compra y llevar a los niños al médico. Las asistentas por horas se dedican fundamentalmente a limpiar la casa; en menor medida, a planchar y lavar la ropa. 


\section{TABLA 13}

Tareas domésticas ordinarias que realiza la ayuda doméstica remunerada (Porcentaje que realiza sobre total entrevistadas con ayuda doméstica remunerada)

\begin{tabular}{|c|c|}
\hline Tipo de tarea & Porcentaje que realiza \\
\hline Cuidar niños en edad preescolar .................. & 25,5 \\
\hline Cuidar niños después del colegio & 29,9 \\
\hline Llevar/traer niños al colegio & 23,3 \\
\hline 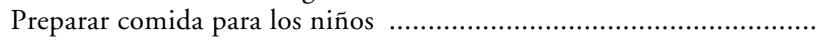 & 23,6 \\
\hline 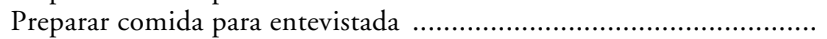 & 21,1 \\
\hline Preparar comida marido entrevistada & 20,9 \\
\hline Limpiar la casa .................................. & 85,5 \\
\hline Lavar ropa & 51,2 \\
\hline Planchar & 57,7 \\
\hline Coser & 28,7 \\
\hline Hacer la compra & 10,6 \\
\hline Llevar a los niños al médico & 7,0 \\
\hline
\end{tabular}

Fuente: Encuesta de Compatibilización Familia-Empleo.

Con menos frecuencia, excepto en el caso de las internas y de las canguros, la ayuda doméstica remunerada asume tareas de carácter extraordinario, en especial quedarse con los hijos si están enfermos mientras los padres trabajan y cuidar a los hijos durante las vacaciones escolares.

Tal como se ha comentado anteriormente, la decisión de contratar a alguien para que a cambio de una remuneración asuma una parte de las tareas domésticas es generalmente difícil, ya que supone dedicar a ello una parte importante de los ingresos familiares. Con frecuencia, el cálculo se hace sobre los ingresos de la mujer, lo cual hace que su coste de oportunidad se perciba como elevado, apoyando la teoría de la elección racional aplicada a la división de roles en la familia (Becker, 1987). La diferencia entre lo que gana la madre trabajadora y lo que se paga a alguien por realizar una parte del trabajo doméstico debe ser tal que «justifique» el trabajo extradoméstico de la mujer. Es decir, subyace la idea de que la ayuda doméstica remunerada "sustituye» a la mujer en el hogar (no así a los hombres). Sin embargo, a pesar de la menor «racionalidad» económica en términos de lógica familiar, se superponen frecuentemente otras lógicas relacionadas con la independencia económica de las mujeres (Tobío et al., 1998: 54-84). Para la mayor parte de las entrevistadas, la ayuda doméstica remunerada es muy importante: un $18,8 \%$ afirma que sin ella no podría trabajar, un $41,5 \%$ que es muy importante y un $27 \%$ que es importante. Sólo un $4 \%$ de las entrevistadas que tienen ayuda doméstica remunerada afirma que ésta es poco o nada importante. 
La percepción de la importancia de la ayuda doméstica remunerada sólo aparece asociada claramente a la percepción de la importancia de la red familiar. Cuanto mayor es la importancia que se le da a la ayuda de la red familiar, menor es la que se le atribuye a la ayuda remunerada. El 31\% de las entrevistadas sin familia en su localidad de residencia (entre las que tienen ayuda remunerada) afirma que sin ésta no podría trabajar. El $88 \%$ de las que afirman que la ayuda que les presta la red familiar es poco o nada importante dice que la ayuda remunerada es al menos importante $(36,6 \%$ afirma que sin ella no podría trabajar).

En resumen, la existencia de la ayuda doméstica remunerada está en primer lugar asociada a la capacidad económica de las madres trabajadoras, así como al número de hijos. Se asocia también a la ayuda de la red familiar, y en especial de su protagonista principal, la abuela materna. Hay una complementariedad entre los recursos principales con los que cuentan las madres trabajadoras, de tal manera que la ayuda doméstica a cambio de una remuneración se hace más importante cuando no se puede contar con la red familiar y viceversa, excepto entre las clases altas, entre las que la ayuda de la familia extensa se limita a situaciones especiales. Parece así haber una lógica social que rige la división del trabajo entre los agentes principales que colaboran en la organización doméstica. Se trata de una red femenina en cuya base está la solidaridad de la generación precedente. La ayuda de las abuelas se intensifica cuando no se dispone de otros recursos. Así, por ejemplo, los hijos de las madres que trabajan en el servicio doméstico cuidando a los hijos de las madres trabajadoras de clase media son cuidados por las abuelas y otras parientas femeninas, no sólo en España, sino también en otros países como Estados Unidos (Romero, 1997). Otra estrategia frecuente entre las inmigrantes es dejar a los hijos en su país de origen al cuidado de las abuelas.

\section{EL REPARTO DE TAREAS CON LA PAREJA MASCULINA}

El hecho de que las mujeres trabajen no evita el fuerte desequilibrio en la realización de las tareas domésticas en las parejas españolas, puesto de manifiesto en numerosas investigaciones. Entre otras, se puede señalar la Encuesta Metropolitana de Barcelona de 1990, que, aunque registra una pequeña mejora respecto de los datos de 1986 (Izquierdo et al., 1988: 31), muestra que el $44 \%$ de los hombres no dedica nada de tiempo al trabajo doméstico (Prats Ferret et al., 1995: 56). Una encuesta realizada en 1995 en el País Vasco a mujeres que trabajan fuera de casa registra que sobre una escala de puntuación de 0-10 aplicada a la cantidad de trabajo doméstico que realizan hombres y mujeres que viven en pareja, el $80,7 \%$ de las mujeres se sitúa entre 6 y 10 , cifra que se reduce a un 13,9\% en el caso de los hombres (Emakunde, 1997: 168). 
Datos referidos a nuevas familias (parejas con al menos un hijo de 13 años o menos que convive) en la corona metropolitana de Madrid muestran que la pauta de división del trabajo cuasi-igualitaria es muy minoritaria, alcanzando entre el 8 y el 12\%, según los tipos de tareas que se incluyan (Meil, 1999: 90106). En lo que se refiere a mujeres trabajadoras para el total español, un estudio sobre el uso del tiempo muestra que su dedicación al trabajo doméstico es de 3,28 horas/día de lunes a viernes, 3,96 los sábados y 3,26 los domingos. Los datos para los hombres que trabajan son, respectivamente, $0,59,0,85$ y 0,57 (Ramos Torres, 1990: 55). Un estudio comparativo europeo realizado en 1991, mencionado anteriormente, muestra que los hombres españoles que viven en pareja son los que en mayor proporción no realizan ningún tipo de trabajo doméstico: 76,6\% según ellos mismos y 79,7\% según sus parejas femeninas (Eurobarometre, 1991).

Según datos ECFE, de las dieciocho tareas domésticas estudiadas en los hogares de las madres trabajadoras que viven en pareja, no hay ninguna que sea realizada mayoritariamente por los hombres, y sólo tres que en la mayor parte de los casos realizan ambos miembros conjuntamente: levantarse por las noches para atender a los niños, ayudar a los niños en los deberes y estar con los niños después del colegio, aunque hay que señalar que, en estos dos últimos casos, en una cuarta parte de los hogares nadie realiza esa tarea. Lo que más frecuentemente hacen las entrevistadas solas es poner la lavadora (77\%), planchar (76\%), limpiar los baños $(70 \%)$, tender la ropa $(68 \%)$, preparar la comida $(66,5 \%)$ y limpiar los cristales (65\%). Las tareas que menos realizan los hombres solos son: limpiar los baños $(2 \%)$, planchar $(2 \%)$, quitar el polvo $(3 \%)$, poner la lavadora $(3 \%)$, hacer las camas (4\%) y llevar a los niños al médico (5\%). Entre las tareas que menos realizan los hombres solos hay algunas que son asumidas mayoritariamente por las mujeres, en especial las relacionadas con la limpieza, el cuidado de la ropa y la preparación de comida, mientras que las que se refieren al cuidado de los niños en una elevada proporción son asumidas conjuntamente por ambos miembros de la pareja. No está claro, sin embargo, qué significa exactamente en cuanto a cargo del trabajo doméstico la elaboración conjunta de tareas.

Las dos variables más claramente asociadas al reparto de tareas son el nivel socioeconómico correspondiente a la ocupación de la mujer y del hombre. Actúan, sin embargo, en un sentido diferente en cuanto a la participación de los hombres en el hogar. Cuando la ocupación de la mujer tiene una mayor cualificación y remuneración, aumenta la participación del hombre en el trabajo doméstico, tanto de las tareas que realiza él solo como de las que realizan conjuntamente ambos miembros de la pareja, disminuyendo las que realizan las mujeres solas. Aumentan también las tareas que no realiza ninguno de los miembros de la pareja (que previsiblemente asume la ayuda doméstica remunerada). 


\section{TABLA 14}

Tareas según quién las realiza: entrevistada, pareja, ambos o ninguno (Porcentajes horizontales)

\begin{tabular}{|c|c|c|c|c|}
\hline Tarea & Entrevistada & Pareja & Ambos & Ninguno \\
\hline Preparar el desayuno & 49,6 & 8,1 & 38,0 & 4,5 \\
\hline Preparar la comida .... & 66,5 & 6,7 & 18,4 & 8,3 \\
\hline Fregar cacharros/recoger mesa ... & 55,8 & 6,5 & 30,7 & 7,1 \\
\hline Hacer la compra ........................ & 49,7 & 6,4 & 42,3 & 1,6 \\
\hline 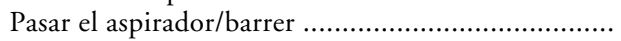 & 60,1 & 5,2 & 23,0 & 11,8 \\
\hline Limpiar los cristales & 65,0 & 5,0 & 16,1 & 14,0 \\
\hline Limpiar los baños & 69,9 & 1,9 & 15,1 & 13,1 \\
\hline Quitar el polvo & 62,3 & 2,7 & 20,9 & 14,1 \\
\hline 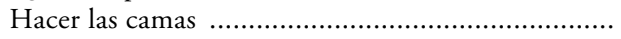 & 60,7 & 4,3 & 28,5 & 6,5 \\
\hline 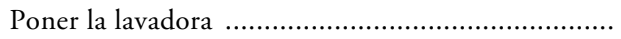 & 77,1 & 3,0 & 14,0 & 5,9 \\
\hline Tender la ropa & 68,4 & 5,7 & 18,1 & 7,8 \\
\hline 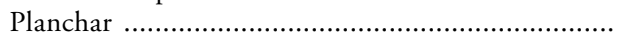 & 76,4 & 2,0 & 9,9 & 11,7 \\
\hline Llevar/traer niños centro escolar ................................. & 30,1 & 8,9 & 24,9 & 36,1 \\
\hline 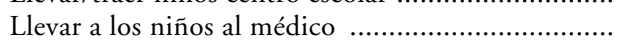 & 48,6 & 4,7 & 39,2 & 7,5 \\
\hline Ayudar a los niños en los deberes .............................. & 29,5 & 10,2 & 38,3 & 22,1 \\
\hline Estar con los niños después del colegio ...................... & 33,1 & 8,2 & 33,7 & 25,0 \\
\hline Levantarse noches para atender niños ....................... & 40,0 & 5,1 & 46,5 & 8,3 \\
\hline Regar las plantas & . 54,9 & 11,8 & 17,6 & 15,7 \\
\hline
\end{tabular}

Fuente: Encuesta de Compatibilización Familia-Empleo.

\section{TABLA 15}

Quién pasa el aspirador/barre por nivel socioeconómico de la entrevistada (Base $=$ madres trabajadoras que viven en pareja) (Porcentajes verticales)

\begin{tabular}{|c|c|c|c|c|}
\hline & Alto & Medio & Bajo & TOTAL \\
\hline Entrevistada .............................. & 44,0 & 60,5 & 67,0 & 59,8 \\
\hline ㄱ․ & 7,9 & 4,7 & 4,4 & 5,2 \\
\hline 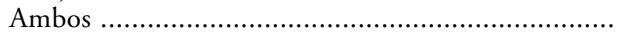 & 27,2 & 22,2 & 22,2 & 23,1 \\
\hline 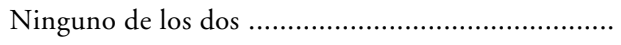 & 20,9 & 12,6 & 6,4 & 12,0 \\
\hline TOTAL & 100 & 100 & 100 & 100 \\
\hline
\end{tabular}

Fuente: Encuesta de Compatibilización Familia-Empleo (chi cuadrado significativo al 0,000; 0 casilla frecuencia esperada $<5$ ).

Cuando el nivel socioeconómico correspondiente a la ocupación de la pareja masculina es más alto, las tareas domésticas que hace la mujer sola disminuyen, pero no aumentan las que hace el hombre solo, aunque sí lo hacen 
las conjuntas y, sobre todo, las que no asume ninguno de los miembros de la pareja, ya que previsiblemente se hace cargo alguien a cambio de un salario.

\section{TABLA 16}

Quién hace las camas por nivel socioeconómico de la entrevistada (Base $=$ madres trabajadoras que viven en pareja) (Porcentajes verticales)

\begin{tabular}{|c|c|c|c|c|}
\hline & Alto & Medio & Bajo & TOTAL \\
\hline 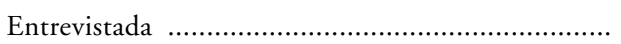 & 41,4 & 65,6 & 63,6 & 60,6 \\
\hline Pareja & 7,3 & 2,4 & 5,6 & 4,3 \\
\hline Ambos …............................ & 40,8 & 25,3 & 26,7 & 28,6 \\
\hline 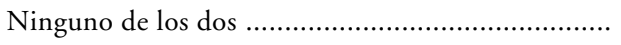 & 10,5 & 6,7 & 4,2 & 6,5 \\
\hline TOTAL & 100 & 100 & 100 & 100 \\
\hline
\end{tabular}

FUENTE: Encuesta de Compatibilización Familia-Empleo (chi cuadrado significativo al 0,000; 0 casilla frecuencia esperada $<5)$.

\section{TABLA 17}

Quién pasa el aspirador/barre por nivel socioeconómico de la pareja de la entrevistada (Base $=$ madres trabajadoras que viven en pareja) (Porcentajes verticales)

\begin{tabular}{|c|c|c|c|c|}
\hline & Alto & Medio & Bajo & TOTAL \\
\hline Entrevistada & 56,3 & 63,7 & 58,6 & 59,8 \\
\hline Pareja & 3,6 & 4,8 & 6,0 & 5,3 \\
\hline Ambos & 21,5 & 18,4 & 27,2 & 23,0 \\
\hline 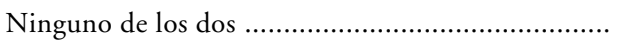 & 18,6 & 13,0 & 8,1 & 11,9 \\
\hline ........................ & 100 & 100 & 100 & 100 \\
\hline
\end{tabular}

FUENTE: Encuesta de Compatibilización Familia-Empleo (chi cuadrado significativo al 0,000; 0 casilla frecuencia esperada $<5$ ).

El diferente efecto de las características del empleo de hombres y mujeres sobre el reparto de tareas domésticas parece indicar que el factor más claramente asociado a una mayor igualdad de género es el nivel de cualificación de la ocupación de la mujer, que cuando es más alto produce un aumento de la participación doméstica de los hombres. Sin embargo, el mayor nivel socioeconómico, tanto derivado de la ocupación de la mujer como del hombre, se traduce en un aumento de la igualdad en el trabajo del hogar a través del incremento de las tareas que realizan conjuntamente. Hay que tener en cuenta, sin 
embargo, que hay una fuerte homogamia en las parejas españolas (Carabaña, 1994). Según datos de la ECFE, el 55\% de las entrevistadas tiene una ocupación del mismo nivel socioeconómico que su pareja masculina.

\section{TABLA 18}

Quién hace las camas por nivel socioeconómico de la entrevistada (Base $=$ madres trabajadoras que viven en pareja) (Porcentajes verticales)

\begin{tabular}{|c|c|c|c|c|}
\hline & Alto & Medio & Bajo & TOTAL \\
\hline Entrevistada ................. & 52,8 & 66,6 & 60,6 & 58,0 \\
\hline 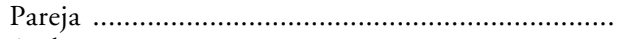 & 1,6 & 2,8 & 6,0 & 11,1 \\
\hline 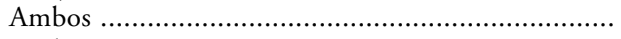 & 33,5 & 24,9 & 29,2 & 25,9 \\
\hline 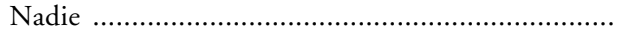 & 12,1 & 5,7 & 4,2 & 4,9 \\
\hline TOTAL . & 100 & 100 & 100 & 100 \\
\hline
\end{tabular}

FUENTE: Encuesta de Compatibilización Familia-Empleo (chi cuadrado significativo al 0,000; 0 casilla frecuencia esperada $<5$ ).

\section{LOS CENTROS ESCOLARES COMO RECURSO PARA HACER COMPATIBLE FAMILIA Y EMPLEO}

Las guarderías y los centros escolares deberían ser uno de los recursos principales para ayudar a hacer compatible la participación en el mundo del trabajo y el cuidado de los hijos. Desde el punto de vista cuantitativo son muy importantes. Prácticamente el cien por cien de los niños de más de tres años está escolarizado (Pérez Díaz et al., 1998: 145) y, según datos de la ECFE, el 73\% de las madres que trabajan y tienen al menos un hijo menor de cuatro años utiliza los servicios de guarderías y centro preescolares. Sin embargo, sólo el 1,5\% de las entrevistadas señala los centros escolares como un factor que facilita la conciliación entre la actividad laboral y las responsabilidades familiares. La mayor parte de los centros, en especial los públicos, no han asumido que la mujer ama de casa disponible en todo momento para el cuidado del hogar y de los hijos no constituye ya la normalidad social. Hay un retraso de la organización social respecto de la nueva realidad, pronto mayoritaria, que constituyen los hogares en los que ambos cónyuges trabajan. Ello se concreta en dos problemas principales: falta de coordinación entre los horarios escolares y laborales, y las vacaciones escolares considerablemente más prolongadas que las que disfrutan los trabajadores.

La falta de coordinación entre los horarios escolares y la jornada laboral constituye un indicador de la escasa asunción por parte de la Administración y las instituciones públicas de las consecuencias de la generalización de la actividad labo- 
ral femenina. Los horarios de guarderías, escuelas y colegios siguen básicamente adaptados — de forma seguramente implícita, inconsciente o como una mera inercia del pasado - a un ritmo temporal característico del ama de casa: entrada tardía, entre 9,00 y 9,30, y salida temprana, entre 16,00 y 17,00 de la tarde. Cuando no hay comedor escolar, a ello se añaden dos desplazamientos más, por lo general entre 12,30-13,30 y 14,30-15,30. Pocas opciones se ofrecen, por lo general, para el cuidado de los niños antes o después de esas horas.

La ECFE aporta información sobre la relación entre los horarios laborales y escolares. Casi un tercio (29\%) de los hijos de las madres trabajadoras entran en la guardería después de que comience su jornada laboral. La falta de coordinación es todavía más acusada en la hora de salida: en un 58\% de los casos los hijos salen antes de que la madre haya finalizado su jornada de trabajo. La situación no mejora, sino que empeora, cuando los niños van al colegio. Un $33 \%$ de las entrevistadas empieza a trabajar antes de que los hijos menores de 12 años entren al colegio, y un 60\% sale cuando sus hijos pequeños ya han terminado su jornada escolar.

¿Cómo se soluciona tal discrepancia horaria? Sorprendentemente, una de cada cuatro entrevistadas que entran a trabajar antes de que abra la guardería lleva ella misma a sus hijos al centro escolar. En un porcentaje igual de casos es la pareja masculina quien lo hace, y a continuación los abuelos y otros parientes. Cuando no hay compatibilidad horaria es la madre quien, en tres casos de cada cuatro, lleva a los niños al colegio.

\section{TABLA 19}

Quién lleva a los niños a la guardería por hora de entrada en la guardería en relación a jornada laboral de las madres que trabajan: antes o después de que éstas empiecen a trabajar

(Base $=$ madres que trabajan con algún hijo en guardería) (Porcentajes verticales)

\begin{tabular}{|c|c|c|c|}
\hline & Antes & Después & TOTAL \\
\hline Entrevistada ............................ & 75,2 & 24,1 & 59,4 \\
\hline 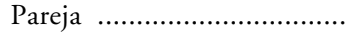 & 17,4 & 24,1 & 19,4 \\
\hline 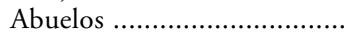 & 2,5 & 18,5 & 7,4 \\
\hline Otros parientes ........................ & 1,7 & 14,8 & 5,7 \\
\hline Otras formas .......................... & 3,3 & 18,5 & 8,0 \\
\hline TOTAL ......................... & 100 & 100 & 100 \\
\hline
\end{tabular}

FUENTE: Encuesta de Compatibilización Familia-Empleo (chi cuadrado significativo al 0,000; 3 casillas frecuencia esperada $<5$ ).

Coherentemente con lo antes señalado acerca de la todavía más acusada falta de coordinación de horarios a la salida de las guarderías, el porcentaje de madres 
que van a recoger a sus hijos a la guardería es menor que por las mañanas: $47 \%$. Ese porcentaje se eleva a un $69 \%$ cuando terminan su jornada laboral antes de la hora de salida de la guardería, pero incluso en caso contrario un tercio de las entrevistadas (34\%) va a recoger a los hijos pequeños al centro escolar. Si la madre cuya jornada todavía no ha finalizado cuando los hijos salen de la guardería no los va a buscar, lo hacen los abuelos (25\%), la pareja masculina $(17 \%)$ o una variedad de personas desde otros parientes a vecinos, amigos, ayuda doméstica remunerada habitual o contratada específicamente para esta finalidad.

\section{TABLA 20}

Quién recoge a los niños de la guardería por hora de salida de la guardería en relación a jornada laboral de las madres que trabajan: antes o después de que éstas salgan del trabajo

(Base=madres que trabajan con algún hijo en guardería) (Porcentajes verticales)

\begin{tabular}{|c|c|c|c|}
\hline & Antes & Después & TOTAL \\
\hline Entrevistada ........................... & 34,3 & 68,7 & 47,4 \\
\hline 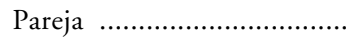 & 16,7 & 25,4 & 20,0 \\
\hline Abuelos ................................. & 25,0 & 1,5 & 16,0 \\
\hline Otros parientes ......................... & 4,6 & 3,0 & 4,0 \\
\hline Otras formas .......................... & 19,4 & 1,5 & 12,6 \\
\hline 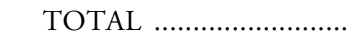 & 100 & 100 & 100 \\
\hline
\end{tabular}

FuENTE: Encuesta de Compatibilización Familia-Empleo (chi cuadrado significativo al 0,000; 2 casillas frecuencia esperada $<5$ ).

Una pauta similar se repite cuando los niños van al colegio. Si los horarios de las madres son compatibles, son éstas quienes mayoritariamente llevan a los niños al colegio; si no es así, aparece un abanico mayor de opciones en comparación con los menores de cuatro años. A la pareja y los abuelos se añaden los niños menores de 12 años que van solos y los que van con la ayuda doméstica remunerada. A la salida del colegio, si la madre todavía no ha terminado de trabajar, lo más habitual es que los niños de menos de 12 años vuelvan solos a casa (25\% de los casos). En otros casos es la propia madre quien los recoge (18\%), los abuelos (18\%) o la ayuda doméstica (9\%).

En síntesis, la incompatibilidad de horarios aparece como un problema grave que afecta a una parte muy importante de las madres trabajadoras, a un tercio aproximadamente por las mañanas a la hora de entrar en los centros escolares y a más de la mitad a la hora de la salida. Pero todavía más sorprendente y preocupante es cómo se solucionan en términos prácticos esos desfases temporales. En primer lugar, son las propias madres cuyos horarios son incompatibles quienes en una proporción destacable se encargan de llevar o 
traer los hijos de los centros escolares, lo cual cabe pensar sea fuente de problemas, conflictos, tensiones o dificultades en su actividad laboral. En segundo lugar aparecen los abuelos, que en casi una quinta parte de los casos se encargan de llevar y traer a los niños de los centros de enseñanza cuando la madre no tiene disponibilidad para hacerlo. Las parejas de las entrevistadas asumen en mayor medida estas tareas cuando ellas no pueden hacerlo, más frecuentemente para llevarlos que para traerlos del colegio, por causas seguramente relacionadas con sus propias limitaciones temporales. La ayuda doméstica remunerada es otro recurso que aparece cuando la madre no puede encargarse de llevar y traer a los niños del colegio, siendo casi inexistente cuando las madres están disponibles. Por último, hay que señalar que hay proporciones destacables de niños pequeños de menos de 12 años que van y, sobre todo, vuelven solos del colegio, lo cual se agudiza cuando la madre tiene problemas de coordinación horaria.

Otra forma de incompatibilidad entre el mundo escolar y el laboral son las vacaciones, considerablemente más largas y diversificadas en el primero que en el segundo. Los trabajos cualitativos previos a la ECFE indicaron la existencia de una preocupación, y a veces incluso una angustia, ante las dificultades para resolver el cuidado de los hijos durante los períodos de vacaciones escolares en los que los padres tienen que trabajar.

... los horarios, las vacaciones escolares de tres meses, que en verano no sabes dónde dejar a los niños (...) y la verdad es que en el tiempo éste de verano es que es un desarreglo (...) es que es un desarreglo horroroso, las vacaciones éstas de los niños es que son demasiado largas, es que son tres meses que son fatales para todo.

(Entrevista en profundidad, madre sola que trabaja, Madrid, nivel socioeconómico bajo.)

Para la mitad de las entrevistadas, resolver el cuidado de los hijos durante las vacaciones escolares supone algún tipo de dificultad. Un 10\% afirma que la dificultad es mucha, un $15 \%$ que bastante y un $23 \%$ que alguna. La percepción de dificultad se agudiza entre las entrevistadas que tienen jornadas laborales más largas.

El protagonismo principal en el cuidado de los hijos durante las vacaciones corresponde a los abuelos. En más de la mitad de los casos de hijos de menos de 12 años, son ellos quienes asumen esta función. Lo más frecuente es que los niños sean llevados a casa de los abuelos (33\%), aunque tampoco es raro que los abuelos vayan a la casa de sus nietos (20\%). Cuando los abuelos no se encargan de esta tarea, las estrategias son muy variadas. Una de ellas es que los padres se turnen las vacaciones, solución a la que recurre el $10 \%$ de las entrevistadas. Tiene múltiples ventajas (facilidad, comodidad, gratuidad), pero también inconvenientes, ya que la familia no puede disfrutar a la vez de un período de descanso. En otros casos los hijos se quedan solos en casa (9\%), lo cual 
no es seguramente la más recomendable forma de vacaciones. La ayuda doméstica remunerada es otro recurso que utiliza el $9 \%$ de las entrevistadas, a veces contratada específicamente para esta finalidad. También hay madres que llevan a sus hijos al trabajo (7\%), no como solución puntual, sino habitual durante las vacaciones. En ocasiones son otros parientes o los hermanos mayores los que se encargan del cuidado de los hijos más pequeños, y en un reducido número de casos $(2 \%)$ coinciden las vacaciones de la madre y las de los hijos, generalmente cuando su trabajo tiene que ver con la enseñanza. Los niños que acuden habitualmente a actividades lúdicas organizadas por el colegio, por instituciones públicas o de carácter privado (centros de verano, campamentos, etc.) son muy pocos: $3 \%$.

Cuando hay hijos menores de seis años, las estrategias desplegadas para solucionar el problema que plantean las vacaciones escolares son algo diferentes. El recurso a la ayuda doméstica remunerada es más importante (de un 5 a un $13 \%$ ) y se reduce mucho, aunque no desaparece, el porcentaje de niños que se quedan solos en casa (de un 13 a un 5\%).

\section{TABLA 21}

Quién cuida a los hijos durante las vacaciones escolares mientras los padres trabajan según número de hijos de menos de 12 años escolarizados (Base=entrevistadas con hijos $<12$ años escolarizados) (Porcentajes verticales)

\begin{tabular}{|c|c|c|c|}
\hline Quién cuida & Con hijos $<6$ & Sin hijos $<6$ & TOTAL \\
\hline Los llevan a la casa de los abuelos ............................... & 33,8 & 32,6 & 33,2 \\
\hline Los abuelos en casa de la entrevistada ...................... & 20,6 & 19,8 & 20,2 \\
\hline 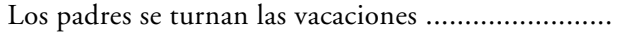 & 9,9 & 10,3 & 10,1 \\
\hline 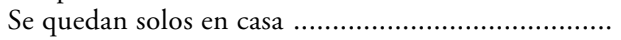 & 4,6 & 13,3 & 9,0 \\
\hline Ayuda doméstica remunerada & 12,7 & 5,0 & 8,8 \\
\hline La entrevistada los lleva al trabajo ............................ & 6,9 & 6,8 & 6,8 \\
\hline 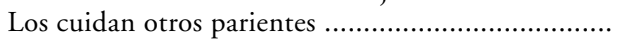 & 3,6 & 2,0 & 2,8 \\
\hline \multicolumn{4}{|l|}{ Coinciden las vacaciones de la entrevistada y de los } \\
\hline 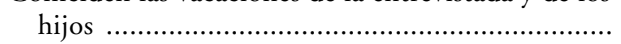 & 1,5 & 3,3 & 2,4 \\
\hline Actividades lúdicas en su localidad ........................... & 0,8 & 2,8 & 1,8 \\
\hline Los cuidan los hermanos mayores .............................. & 1,0 & 1,5 & 1,3 \\
\hline Campamentos/centros de verano ................................ & 0 & 1,8 & 0,9 \\
\hline 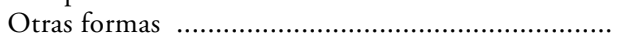 & 3,6 & 1,0 & 2,3 \\
\hline TOTAL & 100 & 100 & 100 \\
\hline
\end{tabular}

FUENTE: Encuesta de Compatibilización Familia-Empleo (chi cuadrado significativo al 0,000; 2 casillas $[7,68 \%]$ frecuencia esperada $<5$ ). 


\section{ESTRATEGIAS ESPACIALES}

La estructura de localizaciones espaciales de las viviendas y el empleo, así como de los equipamientos escolares, comerciales y otros, constituye un factor que hace más fácil o más difícil la doble participación en el mundo familiar y laboral. La tendencia, dominante a lo largo del siglo $\mathrm{XX}$, y en especial a lo largo de los años sesenta, a la separación entre los espacios residenciales y laborales no favorece la compatibilidad entre ambos mundos, sino que es un obstáculo añadido a los otros muchos que se les plantean a las familias en las que ambos cónyuges trabajan o aquellas en las que un único progenitor asume la carga de los hijos (Tobío, 1996).

Superar la creciente distancia entre actividades requiere estrategias específicas para acercar los lugares principales en los que transcurre la vida cotidiana de las madres trabajadoras: la casa propia, el trabajo, los centros escolares y la casa de los abuelos. El ámbito espacial de las actividades laborales de las entrevistadas en la ECFE es más reducido que el de sus parejas masculinas. Más de la mitad de las madres trabajadoras trabajan cerca o muy cerca de sus hogares, cifra que se reduce a un $35 \%$ en el caso de sus parejas.

\section{TABLA 22}

Distancia del lugar de trabajo de las madres trabajadoras y de su parejas masculinas (Porcentajes verticales)

\begin{tabular}{|c|c|c|}
\hline & Entrevistada & Pareja \\
\hline Muy cerca ...... & 21,1 & 12,0 \\
\hline Cerca & 31,3 & 22,6 \\
\hline No muy lejos ................................................ & 22,1 & 21,0 \\
\hline 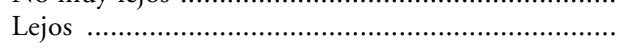 & 17,8 & 25,6 \\
\hline Muy lejos & 5,9 & 12,5 \\
\hline 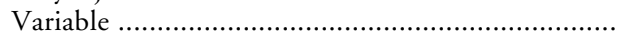 & 1,6 & 5,3 \\
\hline (n) & 100 & 100 \\
\hline
\end{tabular}

Fuente: Encuesta de Compatibilización Familia-Empleo.

Tal como señalan Hanson y Pratt (1995: 93-119), la menor distancia casatrabajo entre las mujeres puede interpretarse en dos sentidos diferentes y complementarios. Por un lado, se trata de una estrategia encaminada a facilitar la compatibilidad entre las responsabilidades familiares y laborales (así como a hacer más racional la vida urbana), pero, por otro lado, supone una limitación respecto de las oportunidades en el mundo del trabajo ya que la condición de cercanía de la vivienda supone una exigencia que restringe las posibilidades de desarrollo profesional.

Aproximadamente cuatro de cada diez entrevistadas (38\%) que viven cerca 
o muy cerca de su trabajo buscaron intencionadamente esa aproximación. Con más frecuencia buscan el trabajo cerca de la casa que al revés, aunque en una proporción destacable de casos $(12,5 \%)$ es al revés. Los datos para las parejas masculinas de las entrevistadas son diferentes al disminuir la intencionalidad en la búsqueda de la aproximación casa-trabajo y, cuando la hay, estar más orientada que en el caso de las mujeres a buscar la casa cerca del trabajo.

\section{TABLA 23}

Razones de la cercanía casa-trabajo de las madres trabajadoras y de sus parejas masculinas

(Base=entrevistadas que trabajan cerca o muy cerca de su casa; parejas que trabajan cerca o muy cerca de su casa) (Porcentajes verticales)

\begin{tabular}{|c|c|c|}
\hline Razones cercanía & Entrevistada & Pareja \\
\hline 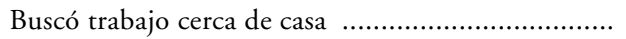 & 25,1 & 16,5 \\
\hline Buscó casa cerca del trabajo & 12,5 & 15,6 \\
\hline 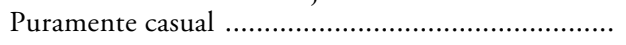 & 61,7 & 67,9 \\
\hline TOTAL ........ & 100 & 100 \\
\hline
\end{tabular}

FUENTE: Encuesta de Compatibilización Familia-Empleo.

Según la percepción de las entrevistadas, los centros escolares están generalmente localizados en un entorno cercano a la vivienda, especialmente las guarderías. El 35\% con algún hijo en guardería dice que está muy cerca de la vivienda, y otro $35 \%$ que está cerca. Sólo el 13\% afirma que la guardería está lejos o muy lejos. En cuanto a los colegios, se dice que están algo más alejados, pero para dos tercios de los casos (63\%) están cerca o muy cerca. Hay un $23 \%$ que afirma que el colegio está muy cerca, entre las que se cuenta la mayoría de las que dicen que lo que más les facilita poder hacer compatible familia y empleo es la proximidad del centro escolar. Sin embargo, el $16 \%$ de las entrevistadas afirma que el colegio está lejos o muy lejos.

\section{ESTRATEGIAS TEMPORALES}

El trabajo a tiempo parcial es escaso en España, aunque es fundamentalmente femenino. La mayor parte de las mujeres tienen largas jornadas de trabajo: sólo el $19 \%$ menos de 30 horas a la semana, y el $62 \%$ más de 40 horas a la semana (INE, 1998: 284). La condición de madre no acorta sustancialmente el número de horas de trabajo según la ECFE. El 19\% de las entrevistadas trabaja menos de 30 horas a la semana, y el $60 \%$ lo hace más de 40 . Las variaciones en la jornada de trabajo están especialmente asociadas al nivel socioeconómico de la ocupación (a más alto, más duración de la jornada) y a la situación profesional (las trabajadoras por cuenta propia trabajan el mayor número de horas y las asalariadas eventuales el menor). 
Más de la mitad de las madres que trabajan (53\%) lo hacen en jornada de mañana y tarde, a lo que se añade un tercio que trabaja solamente por las mañanas. Las entrevistadas con ocupaciones de nivel socioeconómico alto y las que trabajan por cuenta propia son las que más frecuentemente trabajan con jornada partida de mañana y tarde.

Casi la mitad de las madres trabajadoras afirma trabajar las horas que desea, pero un $44 \%$ afirma trabajar más de las deseadas y un $8 \%$ menos horas de las que querría. Son, especialmente, las entrevistadas con ocupaciones de nivel alto las que afirman trabajar más horas de las deseadas, mientras que las de ocupaciones con menor cualificación y remuneración afirman en mayor proporción desear trabajar más horas de las que lo hacen.

Sin embargo, a pesar de la opinión mayoritaria acerca de la excesiva longitud de la jornada laboral y del deseo de trabajar un menor número de horas, si pudieran acceder a una reducción con pérdida de salario, sólo un 15\% elegiría esa opción. Hay también una queja, entre las entrevistadas de mayor nivel de cualificación, hacia las jornadas laborales que se prolongan innecesariamente, más allá del horario oficial.

\section{TABLA 24}

Opinión sobre horas de trabajo por nivel socioeconómico de las madres trabajadoras (Porcentajes verticales)

\begin{tabular}{|c|c|c|c|c|}
\hline & Alto & Medio & Bajo & TOTAL \\
\hline 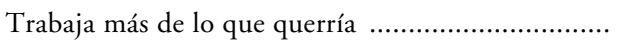 & 46,9 & 46,3 & 39,8 & 44,1 \\
\hline Trabaja menos de lo que querría ............................... & 7,5 & 5,2 & 12,5 & 8,2 \\
\hline 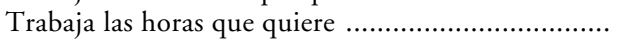 & 45,5 & 48,5 & 47,8 & 47,7 \\
\hline TOTAL & 100 & 100 & 100 & 100 \\
\hline
\end{tabular}

Fuente: Encuesta de Compatibilización Familia-Empleo (chi cuadrado significativo al 0,000; 0 casilla frecuencia esperada $<5)$.

Hay que reorganizarse, hay que planificarse correctamente para que todas las cosas se puedan hacer en un horario... que me parece lógico y humano..., que pueden ser ocho horas, pero ;de la mañana! Que se te pueda extender la jornada hasta las cuatro o las cinco de la tarde, pero no tener reuniones..., pues no sé cómo decirte, olimpicas, olímpicas..., que metes ahi de todo, que no solamente se tratan los temas que interesan, sino otros muchos y que se te van alargando las jornadas pues hasta las ocho, las nueve o las diez de la noche.

(Grupo de discusión, madres trabajadoras, nivel socioeconómico alto, Madrid, 30-39 años.)

Cuando el número de horas de trabajo o su distribución temporal no se puede elegir, las entrevistadas adaptan el tiempo libre que deja la actividad laboral 
para realizar las tareas domésticas, incluyendo las noches, las madrugadas o los fines de semana. Pocas actividades domésticas realizan personalmente las madres trabajadoras por las mañanas, ya que la mayoría trabaja a estas horas del día. Pero no es infrecuente que antes de ir a trabajar realicen ciertas tareas domésticas como hacer las camas (54\%), preparar la comida (17\%), poner la lavadora (15\%) o limpiar los baños (14\%). La hora de comer entre la mañana y la tarde se aprovecha para tender la ropa (11\%) o poner la lavadora (9\%). Menos de una quinta parte de las entrevistadas prepara la comida a la hora de comer, lo más habitual es que se haya preparado antes. La tarde es una parte del día de intensa actividad doméstica para las madres que no trabajan a estas horas. Un tercio aproximadamente de las entrevistadas hace la compra, pone la lavadora y tiende la ropa. Porcentajes algo menores dedican la tarde a planchar (29\%), quitar el polvo (24\%), limpiar los baños (23\%) o pasar el aspirador (21\%). Las noches, después de cenar, no son tampoco siempre un tiempo dedicado al descanso, sino que es entonces cuando se realizan muchas tareas que no se han podido hacer en otro momento, como cocinar $(27 \%)$, poner la lavadora, tender la ropa y planchar. Pero la dedicación más intensa al trabajo doméstico corresponde al fin de semana. Es entonces cuando la mayor parte de las entrevistadas limpian los cristales (54\%), pasan el aspirador $(38 \%)$ o hacen la compra $(37 \%)$.

\section{TABLA 25}

Cuándo realizan las madres trabajadoras las tareas domésticas que realizan ellas personalmente

(Porcentajes horizontales)

\begin{tabular}{|c|c|c|c|c|c|c|c|}
\hline & 1 & 2 & 3 & 4 & 5 & 6 & 7 \\
\hline Preparar la comida ................. & 16,8 & 7,2 & 18,6 & 14,3 & 27,0 & 9,4 & 6,7 \\
\hline Hacer la compra .................... & 7,2 & 9,8 & 5,8 & 34,4 & 1,9 & 37,3 & 3,5 \\
\hline Pasar el aspirador $\ldots \ldots \ldots \ldots \ldots \ldots$ & 9,2 & 8,8 & 6,4 & 20,9 & 2,9 & 37,7 & 14,1 \\
\hline Limpiar cristales ...................... & 5,3 & 7,2 & 3,3 & 14,6 & 1,9 & 53,7 & 13,8 \\
\hline Limpiar los baños ................... & 13,7 & 11,8 & 6,4 & 22,8 & 5,1 & 29,7 & 10,4 \\
\hline 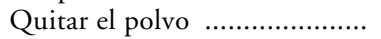 & 13,1 & 10,3 & 5,9 & 23,7 & 3,1 & 32,1 & 11,7 \\
\hline 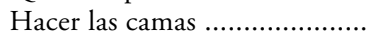 & 54,3 & 16,0 & 5,5 & 9,5 & 2,1 & 5,8 & 6,5 \\
\hline Poner la lavadora ..................... & 15,3 & 9,5 & 8,9 & 32,7 & 18,2 & 9,8 & 5,5 \\
\hline Tender la ropa .......................... & 8,7 & 9,4 & 11,0 & 35,1 & 17,1 & 10,9 & 7,6 \\
\hline 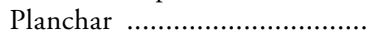 & 4,8 & 4,9 & 3,2 & 28,7 & 19,3 & 28,2 & 10,7 \\
\hline
\end{tabular}

1. Por la mañana antes de ir a trabajar.

2. Por la mañana.

3. A la hora de comer entre la mañana y la tarde.

4. Por la tarde.

5. Por las noches después de cenar.

6. Los fines de semana.

7. Nunca.

Fuente: Encuesta de Compatibilización Familia-Empleo. 


\section{CONCLUSIÓN}

Entre el mundo del trabajo y el mundo de la familia, más que conciliación, hay hoy una relación de contradicción, cotidianamente experimentada por las madres trabajadoras. Las amas de casa y sus parejas masculinas representan un viejo modelo familiar en que la articulación entre esos mundos sólo se establece a partir de la complementariedad de funciones entre hombres y mujeres. La extensión de la actividad laboral femenina rompe la lógica de la división del trabajo basada en roles de género, estableciéndose una nueva articulación familia-empleo a escala individual. Todos, ellas y ellos, madres y padres, tienen en el nuevo modelo la oportunidad, y también cada vez más la obligación, de asumir responsabilidades laborales y de cuidado de los hijos o de otros miembros de la familia que lo necesiten. Y, más allá de los familiares, es la sociedad en su conjunto quien asume como responsabilidad colectiva gestionada a través del Estado el cuidado de los menores y los ancianos.

Este proceso se observa en prácticamente la totalidad de los países desarrollados. Una pluralidad de razones individuales y familiares, económicas y sociales explica por qué las mujeres se incorporan de forma masiva al empleo. No parece que sea un camino con vuelta atrás. El caso español presenta particularidades por el retraso, compensado con la aceleración, de la incorporación de las mujeres al mercado de trabajo. Ello explica, seguramente, la escasa conciencia de la sociedad española ante la magnitud del cambio que está teniendo lugar. Se explica probablemente también porque la mayor parte de los nuevos problemas que plantea el nuevo modelo están siendo solucionados de forma callada, privada e informal entre mujeres, a través de una variedad de estrategias de las que es pieza clave la solidaridad intergeneracional. Las primeras generaciones de madres mayoritariamente activas son escasamente reivindicativas respecto del carácter de "problema social» de las nuevas situaciones que se les plantean, quizá porque todavía hay un cierto temor a la vuelta al pasado, a que si se insiste demasiado en la dificultad de conciliar familia y empleo acaben siendo de nuevo amas de casa.

Muchas de las estrategias que utilizan las madres trabajadoras no serán posibles en un futuro próximo, cuando las últimas generaciones de abuelas inactivas y disponibles vayan desapareciendo y sustituyéndose por abuelas ocupadas y menos proclives a asumir el papel de madres sustitutas. Por otra parte, otras de las estrategias hoy utilizadas son escasamente deseables y tienen seguramente efectos negativos, bien para los hijos o para las madres. La bajísima fecundidad española no es tampoco ajena a los problemas que plantea una situación de transición como la que hoy vivimos. El primer paso para empezar a dar soluciones es reconocer la existencia de un problema. El objetivo de los datos aquí presentados es contribuir a la discusión acerca de la definición de un modelo de futuro que sea realmente capaz de conciliar la participación de todos - mujeres y hombres - en el trabajo y en la familia. 


\section{REFERENCIAS}

Attias-Donfut, C., y Segalen, M. (1998): Grands-Parents. La famille à travers les generations, Odile Jacob, París.

Bloch, F., y Buisson, M. (1996): Faire garder oú garder les enfants: une affaire de femmes, Ministère de Logement, Direction de l'Habitat et de la Construction, París.

BECKer, G. (1987): Tratado sobre la familia, Alianza Editorial, Madrid.

Bourdieu, P. (1980): Le sens pratique, Editions de Minuit, París.

Carabaña, J. (1994): «La constante homogamia educativa», en Economía y Sociedad, 11: 25-42.

Commaille, J. (1993): Les strategies des femmes. Travail, famille et politique, Editions La Decouverte, París.

Daune-Richard, A. M. (1993): «Activité et emploi des femmes: des constructions sociétales différentes en France, au Royaume Uni et en Suède», en Sociétés Contemporains, 4: 125-144.

EMAKUNDE (1997): Estrategias de organización familiar, Gobierno Vasco, Vitoria-Gasteiz.

Eurobarometre (1991): 34, Commission of the European Communities.

Eurostat (1995): Women and men in the European Union, Luxembourg.

FAGNANI, J. (1998): "Helping mothers to combine paid and unpaid work- or fighting unemployment? The ambiguities of French family policy», en Community, Work and Family, 3 (1): 297-312.

FERNÁNDEZ CORdón, J. A. (1999): «La situación sociolaboral de las mujeres», informe de investigación, Fundación Alternativas, Madrid.

Fernández Cordón, J. A., y Tobío, C. (1998): «Las familias monoparentales en España», en REIS, 83.

Giddens, A. (1991): The Constitution of Society, Polity Press, Cambridge.

Guillén, A. M. (1997): "Regímenes de bienestar y roles familiares: un análisis del caso español», en Papers, 53: 45-63.

Hanson, S., y Pratt, G. (1995): Gender, work and space, Routledge, USA y Canadá.

Hantrais, L., y Letablier, M. T. (1996): Families and Family Policies in Europe, Longman, Londres y Nueva York.

INE (1998): Encuesta de Población Activa. Resultados Detallados. Primer trimestre 1998, Madrid.

IzQuierdo, J.; Del Río, O., y RodríGuez, A. (1988): La desigualdad de las mujeres en el uso del tiempo, Instituto de la Mujer/Ministerio de Asuntos Sociales, Madrid.

MeIL, G. (1999): La postmodernización de la familia española, Acento Editorial, Madrid.

Pérez díaz, V.; Chuliá, E., y Álvarez-Miranda, B. (1998): Familia y sistema de bienestar, Argentaria, Madrid.

Prats Ferret, M.; García Ramon, M. D., y Cánoves Valiente, G. (1995): Las Mujeres y el Uso del Tiempo, Instituto de la Mujer/Ministerio de Asuntos Sociales, Madrid.

Ramos TORres, R. (1990): Cronos dividido. Uso del tiempo y desigualdad entre hombres y mujeres en España, Instituto de la Mujer/Ministerio de Asuntos Sociales, Madrid.

Romero, M. (1997): «Who Takes Care of the Maid's Children? Exploring the Costs of Domestic Service», en H. L. Nelson, Feminism and Families, Routledge, Nueva York y Londres, pp. 151-172.

Rubery, J.; Smith, M.; Fagan, C., y Grimshaw, D. (1998): Women and European Employment, Routledge, Londres.

Rubery, J.; Smith, M., y Fagan, C. (1999): Women's Employment in Europe: Trends and Prospects, Routledge, Londres.

Tовío, C. (1996): «Zonificación y diferencias de género», en Astrágalo, 5: 54-60.

Tobío, C.; Arteta, E., y Fernández Cordón, J. A. (1996): «Estrategias de compatibilización familia-empleo. España años noventa», Informe de Investigación, Departamento de Humanidades, Ciencias Políticas y Sociología, Universidad Carlos III de Madrid/Instituto de la Mujer, Madrid.

Tobío, C.; Fernández Cordón, J. A., y Agulló, S. (1998): «Análisis cuantitativo de las estrategias de compatibilización familia-empleo en España», Informe de Investigación, Departamento de Humanidades, Ciencia Política y Sociología/Instituto de la Mujer, Madrid. 
Toвío, C. (1998): «Roles de género y la relación familia-empleo», en Asparkía. Investigació Feminista, 9: 21-44.

Tobío, C., y Fernández Cordón, J. A. (1999): «Monoparentalidad, trabajo y familia», en Revista Internacional de Sociología, tercera época, 22: 67-97.

VAliente, C. (1997): «Las políticas de cuidado de los niños a nivel nacional en España (19751996)», en Papers, 53: 101-136.

\begin{abstract}
The fast spread of female incorporation into the labour market is accompanied in Spain by a scanty presence of part-time work, insufficient child care services, and a limited participation of men in household chores. In such a context, the question raised is how working mothers manage to reconcile, in practical terms, their dual responsibility of working and taking care of the family. Starting out from the concept of strategy, an investigation is made into the resources which most favour the reconciliation between the world of work and the family domain, whilst also indicating their limitations. Amongst other topics tackled, are the help given by the extended family, paid help, schools, spacial strategies and temporal strategies. The conclusion reached is that between family and work there is, today, a relationship of contradiction which those who most directly personify it - working mothers — resolve in a private, informal and not always satisfactory way. The information used is based on the Family-Job Reconciliation Survey which was carried out in 1998 on a representative sample of Spanish working mothers, complemented with data of a qualitative nature.
\end{abstract}

